\title{
Health-Related Quality of Life and Rhinitis Control Measures in Allergic Rhinitis
}

Melina Makatsori, MD, MRCP, MA, MSc ${ }^{1, *}$ Christopher Koulias, $M D^{2}$ Moises A. Calderon, MD, $P h D^{1}$

\author{
Address \\ ${ }^{*}, 1$ Section of Allergy and Clinical Immunology, Imperial College London, NHLI, \\ Royal Brompton Hospital, London, UK \\ Email: melina.makatsori08@imperial.ac.uk \\ ${ }^{2}$ Allergy Unit "D. Kalogeromitros", 2nd Department of Dermatology and \\ Venereology, Medical School, Athens University, "Attikon" University Hospital, \\ Athens, Greece
}

Published online: 9 January 2014

(C) Springer International Publishing AG 2014

Keywords Health-related quality of life - Patient-reported outcomes - Rhinitis control measures - Allergic rhinitis

\section{Opinion statement}

The personal burden of illness as perceived by allergic rhinitis patients extends beyond clinical symptoms with an impact on sleep, social life and daily activities including work and school performance. Health-related quality of life (HRQoL) is now recognised as one of the most important patient-reported outcomes in patients with allergic rhinitis and asthma. Several validated HRQoL instruments are currently available, aiming to quantify the degree to which the medical condition or its treatment impacts on the individual's life in a valid and reproducible way. Recently, there has been an increased interest in disease control, and it is now being considered as an alternative to disease severity in the management of allergic rhinitis patients. To that effect, different rhinitis control measures have been developed and validated. This review will explore the HRQoL instruments and rhinitis control measures currently available, and discuss their advantages and disadvantages and potential use in research and clinical practice.

\section{Introduction}

Allergic rhinitis, being the most common allergic disorder, is recognised as an emerging global health issue conservatively estimated to affect 500 million people of all ages, socio-economic conditions and ethnic groups [1]. It is defined as a symptomatic disorder of the nose induced by an IgE-mediated inflammation of the membranes lining the nose after allergen exposure, and presents with sneezing, rhinorrhoea, nasal obstruction and nasal itching [2], accompanied in the majority of patients with ocular symptoms. Impor- 
tant comorbidities, such as asthma, rhinosinusitis or otitis media, are also frequently present [3]. Fifteen to $38 \%$ of patients with allergic rhinitis are estimated to suffer with asthma [1], and rhinitis on its own has been found to be an important predictor of adult-onset asthma [4].

Although studies on the prevalence of allergic rhinitis in different populations present with great heterogeneity due to different criteria and methodological approaches used, the reported prevalence ranges from $10 \%$ to $30 \%$ for adults and up to $40 \%$ for children, with differences among and within countries $[5,6]$.

It is well recognised that although not life-threatening, allergic rhinitis can adversely affect the quality of life of affected patients, and cause a significant burden on both the individual and society [7]. The symptoms have the potential to lead to both physical and mental complications, with allergic rhinitis patients reporting problems sleeping, increased fatigue, impaired cognition, and psychological distress [8, 9]. In addition, the symptoms of allergic rhinitis have been shown to compromise the ability to perform at work or school $[10,11]$.

Recently, increased interest has appropriately been shown to the patient's viewpoint about their illness and treatment options. All these viewpoints, which in- clude symptoms, illness perception, quality of life, satisfaction with or adherence to treatment, health status, well-being, work productivity, as well as control of disease reported directly by the patients, without interpretation by physicians or others, are grouped under the definition of Patient-Reported Outcomes (PROs) [12•]. PROs focus the attention only on the patient, because she/he is the only person authorised to provide information about the personal experience of the disease, treatment and care [13].

Among these PROs, health-related quality of life (HRQoL) has been the one most extensively studied. HRQoL is now recognized by the Global Allergy and Asthma European Network (GA2LEN) as one of the most important PROs in patients with rhinitis and asthma $[13,14 \bullet]$. The European Medicines Agency (EMA) has also suggested that in non-life threatening chronic disease, results based on PROs could provide a useful indication for the choice of drug, when two or more drugs are shown to have similar efficacy [15].

In this review, we will discuss the different healthrelated quality of life instruments used in clinical trials of allergic rhinitis, as well as the ones applicable in clinical practice. We will also review new developments in this area, particularly the various rhinitis control measure tools that have been developed.

\section{Health-related quality of life (HRQoL)}

Quality of life has been defined by the World Health Organisation as "the individual's perception of their position in life in the context of the culture and value systems in which they live and in relation to their goals, expectations, standards and concerns" [16]. Health related quality of life (HRQoL) is the component of overall quality of life that pertains to an individual's health. This includes the psychological, physical and social aspects of one's quality of life that are related to someone's health [17].

HRQoL instruments can be used to assess the impact of an illness on a patient as perceived by the patient. They are the only systemic scientific way to study differences in HRQoL between patients with a similar level of objective clinical impairment [18]. HRQoL instruments can also be used as outcome measures for studying the impact of diagnostic or management interventions from the patient's perspective. They have also been suggested as one of the most relevant secondary outcomes in allergen immunotherapy trials [19].

HRQoL can be measured using qualitative or quantitative methods. Qualitative methods are useful for identifying new areas of interest and forming hypotheses due to their relatively open structure. Quantitative research may be 
described as the numerical representation of observations to describe and explain HRQoL. Quantitative methods require validated instruments and provide precise outcomes that are useful as research tools or clinical practice.

\section{HRQoL instruments}

There are two major types of HRQoL instruments: generic and disease-specific questionnaires.

\section{1). Generic questionnaires}

These are intended for general use and can be used to evaluate and compare different disease states, treatment interventions and populations. Typically, they include consideration of physical functioning, ability for self-care, physiological status, level of pain or distress, and amount of social integration. Generic instruments can also serve as health profiles [20]. However, the disadvantages are that they may not focus adequately on problems specific to a particular disease, and they simultaneously measure the impact of comorbid conditions.

The best-validated and most commonly applied generic questionnaire is the Health Status Questionnaire Short Form-36 (SF-36). It is comprised of 36 questions in nine health domains, and renders mental component summary scores, as well as a psychometrically based physical component summary. This has been shown to be a valuable tool in discriminating between patients with perennial allergic rhinitis and healthy subjects [21]. It has been used as a secondary outcome in allergic rhinitis trials assessing efficacy of pharmacological treatments [22-24], as well as allergen immunotherapy [25, 26].

Other generic HRQL questionnaires that have been used in allergic disorders are the Medical Outcome Study Short Form-20 (SF-20) [27], the Satisfaction Profile (SAT-P) [25], the EuroQol Questionnaire (EQ-5D) and 15Dimensional Health-related QOL (15D) [28].

The Satisfaction Profile (SAT-P) questionnaire asks individuals to evaluate their satisfaction about 32 life aspects with reference to the last month (on 32 visual analogue scales) independently of their objective health status. It provides 32 individual scores and five factor scores, all ranging from 0 (lowest level of satisfaction) to 100 (highest level of satisfaction). SAT-P has been used in seasonal allergic rhinitis and was found to correlate with the SF36 data [29].

The EQ-5D instrument is an alternative health state descriptive system that consists of five dimensions: mobility, self-care, usual activities, pain/ discomfort and anxiety/depression. Each item has three levels: no problems, some problems, or extreme problems. Thus, this system represents 243 possible health states [28].

The 15D questionnaire can also be used both to obtain a profile across 15 dimensions and a single index score ranging from 0 (being dead) to 1 (full health) [28].

2) Disease-specific questionnaires Disease-specific instruments are more responsive than generic instruments and they can be targeted to a specific population, disease or function. Specific instruments are more likely to detect clinically important impairments specific for a particular disease or HRQoL differences over time, and are better suited to evaluate the impact of interventions for specific diseases [30, 31].

In patients with allergic rhinitis and rhinoconjunctivitis, the Rhinoconjunctivitis Quality of Life Questionnaire (RQLQ) developed by 
Juniper et al. is the most widely used questionnaire in assessment of HRQoL. This instrument has been adapted in several forms: the standardised form of RQLQ, Nocturnal RQLQ for measurement of nocturnal rhinitis, age-specific: the Adolescent RQLQ for patients 12-17 years of age and the Paediatric RQLQ for patients 6-12 years and the miniRQLQ [32-35].

The standardised version of the RQLQ has 28 questions in seven domains (practical problems, activity limitations, sleep problems, emotional condition, nasal symptoms, eye symptoms, non-nose/eye symptoms), all of which are scored by the patients using a seven-point Likert scale ranging from 0 (not troubled/none of the time) to 6 (extremely troubled/all the time). For the domain "activities", three items can be freely selected by the patient from a list of 29 activities. These activities should be the three considered by the patient to be most affected by the disease [32]. This instrument has been translated into different languages. It has been tested in adult patients with seasonal, perennial as well as intermittent and persistent allergic rhinitis, and is used extensively in both clinical studies and clinical practice [31]. In controlled clinical trials, a difference of 0.5 or greater in RQLQ domains between active and placebo-treated patients is regarded as clinically relevant [34].

The Mini Rhinoconjunctivitis Quality of Life Questionnaire (miniRQLQ) only has 14 of the 28 questions of the standardised version of the RQLQ. Although this is a useful tool for group studies such as clinical trials and cross-sectional surveys, the standardised version is considered to be more sensitive for use in clinical practice [36].

The Nocturnal Rhinoconjunctivitis Quality of Life Questionnaire (NRQLQ) was designed to measure the functional problems that are most troublesome to patients with nocturnal allergic rhinoconjunctivitis. The instrument consists of 16 items over four domains (sleep problems, symptoms during sleep time, symptoms on waking and practical problems). The NRQLQ asks patients to recall their experiences during the previous week and score each item on a seven-point scale. A validation study has shown that the NRQLQ has strong evaluative and discriminative measurement properties and can be used in both clinical practice and clinical trials [35].

It is important to use age-specific questionnaires, as different aspects of HRQoL can be affected in different age groups. The Adolescent RQLQ has been specifically designed for adolescent rhinoconjunctivitis clinical trials for patients 12-17 years of age, while the Paediatric RQLQ is applicable to 612 year old patients.

The Adolescent RQLQ has 25 questions in six domains (nose symptoms, eye symptoms, practical problems, activity limitation, nonhayfever symptoms, and emotional function) [33]. The items identified by 12 - to 17 -year-old patients were not identical to those previously identified by adults. This suggests that impairment of quality of life may not be the same in the two groups, and that it is appropriate to have a separate questionnaire. Interestingly, adolescents in the validation study indicated that they experience important problems in doing their work (school), and also they are troubled by generally not feeling well; these were not considered important by adults. 
The Paediatric RQLQ has 23 questions in five domains (nasal symptoms, ocular symptoms, other symptoms, practical problems, and activities) and children are asked to score their experiences during the previous 7 days [37]. Of note, children are not as bothered by emotional problems or limitations of activities, as is the case for adults and adolescents. Validation of this questionnaire has found that children provide reliable and accurate responses and the Paediatric RQLQ can be used in clinical trials, clinical practice, and surveys.

The RQLQ has been used in many well-powered clinical trials as a secondary outcome both for subcutaneous $[38,39]$ and sublingual immunotherapy [40-43] in adults and children [44]. These studies have shown that immunotherapy improves HRQoL in allergic rhinoconjunctivitis patients. Furthermore, this seems to parallel the clinical outcomes of a reduction in symptoms and/or medication intake.

The RQLQ can also be a useful tool in daily clinical practice. For example, the patient can fill in the questionnaire prior to their clinical appointment. Review of this by the clinician can identify how the patient is doing and identify specific aspects that need to be explored further in the consultation [30]. Furthermore, repeated measurements can allow improvements or exacerbations to be easily identified, as well as enable assessment of response to treatment. The main drawback of the RQLQ is that it comprises a oneweek evaluation, and days with significant symptoms may be missed. Furthermore, it does not specifically assess allergic rhinitis control, nor predict future outcomes of treatment [12•].

Of note, the RQLQ only evaluates HRQoL in relation to allergic rhinoconjunctivitis symptoms but not to allergic asthma, although both diseases are linked and often coexist. The Rhinasthma questionnaire consists of 30 items and has been developed and validated for assessing the functional, physical, and emotional status of adult patients with allergic rhinitis and asthma [45]. It evaluates the HRQoL in the previous 2 weeks.

Following on from the Rhinasthma questionnaire, the RhinAsthma Patient Perspective (RAPP), a simple eight-question questionnaire with good measurement properties and sensitivity to health changes, has been found to provide a valid, reliable and standardised HRQoL measurement in patients with asthma and comorbid allergic rhinitis in clinical practice [46].

Other specific questionnaires include the ESPRINT-15, which is a validated specific instrument to assess HRQoL in allergic rhinitis that is particularly recommended for use in Spanish-speaking populations [47]. It contains 15 items grouped into four dimensions: symptoms (five items), activities of daily living (three items), sleep disturbances (three items), psychological impact (three items), and one general question. All items are scored on a seven-point Likert scale, ranging from 0 (minimum impact on HRQoL) to 6 (maximum impact on HRQoL). The 15 items provide an overall score on a five-point scale (0-excellent to 4-bad). This questionnaire has been used in a trial assessing the effect of an antihistamine on allergic rhinitis [48].

The Work Productivity and Activity Impairment-Allergy Specific Questionnaire has been developed and validated to measure the effect of allergic rhinitis on work productivity (adults), classroom productivity (students), and regular activities. It assesses function-related end points, providing a measure of the economic impact of allergic rhinitis and the potential of 
therapeutic interventions [49]. The medical treatment of rhinitis has been found to improve work productivity in persistent and also seasonal allergic rhinitis using this tool $[50,51]$.

\section{Rhinitis control measures}

As has already been done with asthma, where patients have similar difficulties in correctly evaluating the control of their illness, there has recently been an increased interest in developing and validating self-assessment control measure scores for assessing allergic rhinitis clinical control.

The Rhinitis Control Assessment Test (RCAT) was developed to measure rhinitis symptom control from the patient's perspective. It aims to identify patients whose nasal symptoms, ocular symptoms, or both, might warrant a change in management, referral to an allergy specialist, or both. It has six items that include nasal congestion, sneezing, watery eyes, sleep problems caused by rhinitis, activity avoidance, and rhinitis symptom control assessed over the previous one-week period. Responses are measured on five-point Likert-type scales and the scores range from 6 to 30, with higher scores indicating better rhinitis control $[52,53]$. Aside from being a useful tool for identifying patients experiencing problems with rhinitis symptom control, the RCAT might also be useful in assessing the effect of therapeutic interventions and in identifying deterioration in rhinitis symptom control, and thus can be a useful tool both in clinical practice and for clinical research. A score of 21 or less is considered to be useful in identifying patients who are experiencing control problems. The recommended minimal important difference (MID), which is the minimum change in RCAT score that might be clinically meaningful, was found to be greater than 2.4 points. This suggests that differences in mean RCAT scores of greater than 2.4 points between groups are likely to be clinically significant [54].

In addition, a study of 1,051 patients compared the MiniRQLQ and the RCAT to each other regarding content and predictive abilities. This found that baseline RCAT scores were strongly correlated with baseline MiniRQLQ scores in both allergic and non-allergic patients. Baseline MiniRQLQ and RCAT scores were significantly related to patient reports of missed school/ work, medication use, and effectiveness over the next 3 months, and to dispensing during the following year of total, and some individual, rhinitis medications [55].

The Allergic Rhinitis Control Test (ARCT) was developed based on the Asthma Control Test (ACT). It includes five items scored from 1 to 5, assessing the rhinitis over the two previous weeks. The questionnaire was validated by testing it in 902 patients before treatment and two weeks after treatment. The score at inclusion correlated significantly $(p<0.0001)$ with the patient's overall clinical status and the impact of allergic rhinitis on social and sporting activities. A score of 20 was found to be the optimal cut-off for poor versus well-controlled rhinitis. It was concluded that this self-completion questionnaire could be used in daily practice at each consultation to determine, in a standardised manner, the level of control of the allergic rhinitis of an individual patient [56]. 
A tool developed to assess both asthma and rhinitis is the Control of Allergic Rhinitis and Asthma Test (CARAT). Initially, a version consisting of 17 questions was developed to be used in the concurrent management of these diseases, as recommended by the Allergic Rhinitis and its Impact on Asthma (ARIA) guidelines [57]. This was then shortened to the CARAT10, consisting of ten questions that refer to the control of these diseases in the previous 4 weeks. Seven questions address the frequency of symptoms, one sleep impairment, one activities limitation and one the need for more medication. The response options for all questions are four-point Likert scales. The range of possible scores for CARAT10 is $0-30$, 0 being the complete absence of control. This tool has been found to have good test-retest reliability, responsiveness and longitudinal validity, making it useful to compare groups in clinical studies and also in clinical practice [58, 59].

There are no studies currently comparing these tools with each other. Also, they have not yet been tested in allergen immunotherapy randomised control trials. Furthermore, additional development and testing of these tools is required so that they can also be applicable in paediatric populations [60].

\section{Patient satisfaction}

Patient satisfaction has been shown to affect patients' health-related decisions and treatment-related behaviours, which in turn have a substantial effect on the success of treatment outcomes.

The 'Patient Benefit Index' (PBI) is a global score of patient relevant benefit. It is a calculated index that compares the patient rating before (Patient Needs Questionnaire, PNQ) and after treatment (Patient Benefit Questionnaire, PBQ). Both questionnaires consist of a 25-item list that the patient rates with respect to personal importance, from 'not at all' to 'very'. The PBI is computed by dividing each rating on a need item by the sum of all ratings in the PNQ, and multiplying this fraction with the respective benefit rating (PBQ). The PBI is the sum of these products and ranges from 0 'no benefit' to 4 'maximum benefit'. A PBI greater or equal to 1 is considered as a threshold of 'relevant benefit'. It has been validated in 104 patients with allergic rhinitis and has been found to be a feasible, reliable and valid instrument known as PBI-AR, for the standardised assessment of patient-relevant benefits in the treatment of allergic rhinitis [61].

Satisfaction with treatment is especially relevant in long-term treatments such as allergen immunotherapy. A Satisfaction Scale for Patients Receiving Allergen Immunotherapy (ESPIA) questionnaire has been developed. This was assessed in 429 patients undergoing allergen immunotherapy (AIT). The overall score for the ESPIA questionnaire was strongly associated with months receiving AIT, type of allergic rhinitis and intensity, presence of conjunctivitis, self-perceived health status, effect of allergic rhinitis on daily life, and expectations about the AIT treatment. This has been found to have good sensitivity to change for 
improved health status, and was recommended for use in clinical practice [62].

Recently, a new Allergic Rhinitis Treatment Satisfaction and Preference (ARTSP) scale was evaluated in 185 allergic rhinitis subjects. The ARTSP was designed to differentiate between treatments based on patient-reported satisfaction in comparative clinical trial settings. This scale was found to be a reliable, valid, and responsive measure of patient evaluations of alternative therapies, providing detailed information about treatment characteristics that are likely to influence adherence levels and subsequent allergic rhinitis clinical control. A shorter version of the ARTSP is being developed that will better support decision making in the clinical practice setting [63].

\section{Discussion}

Assessment of PROs is gaining increasing importance both in research and in clinical practice. This approach enables better understanding of patient-related factors influencing management outcomes, as well as identifying patient subgroups that can benefit from specific treatments. It further allows tailoring of treatment to address PROs and improve rhinitis management [14•]. Currently, assessment of PROs is rarely the primary, but rather a secondary outcome in clinical trials. The development of clinical trials in which PROs are the primary or co-primary outcome is recommended because appropriate tools are available [13].

There are several reliable and validated HRQoL questionnaires that can be used in clinical trials and clinical practice. These include generic and disease-specific questionnaires. Disease specific instruments, such as the RQLQ, have gained acceptance as methods to obtain a measure of disease perception in individuals with allergic rhinitis. Overall, disease-specific tools are recommended when available, while generic questionnaires are useful, especially when comparing different diseases [14•]. The existence of a number of validated questionnaires enables researchers to choose tools pertinent to their study design and population.

Various allergic rhinitis control questionnaires (ARCT, RCAT, CARAT) have also been developed and validated using standardised methods [64]. These vary in the number of questions, as well as the period of evaluation assessed. Of these, only the CARAT score also assesses asthma, which can also coexist in allergic rhinitis patients.

Although the development of these tools is a step in the right direction, the major limitation in assessing allergic rhinitis control, and thus control measure tools, is that unlike other conditions such as asthma, presently there is no universally accepted and validated definition of what constitutes total control. It is therefore difficult to set threshold limits above and below which the degree of control can be classified [12•]. In addition, there are currently no studies comparing these tools in order to identify which of these would be more applicable for clinical trials and/or clinical practice. As previously recommended by the ARIA 
guidelines, it is important that methods for measuring severity and control in allergic diseases are uniform [65]. There is also a need to develop control measures applicable to the paediatric population.

\section{Compliance with Ethics Guidelines}

\section{Conflict of Interest}

Melina Makatsori, Christopher Koulias, and Moises A. Calderon declare that they have no conflict of interest.

\section{Human and Animal Rights and Informed Consent}

This article does not contain any studies with human or animal subjects performed by any of the authors.

\section{References and Recommended Reading}

Papers of particular interest, published recently, have been highlighted as:

- $\quad$ Of importance

1. Brozek JL, Bousquet J, Baena-Cagnani CE, Bonini $\mathrm{S}$, Canonica GW, Casale TB, et al. Allergic Rhinitis and its Impact on Asthma (ARIA) guidelines: 2010 revision. J Allergy Clin Immunol. 2010;126(3):466-76.

2. Bousquet J, Khaltaev N, Cruz AA, Denburg J, Fokkens WJ, Togias A, et al. Allergic Rhinitis and its Impact on Asthma (ARIA) 2008 update (in collaboration with the World Health Organization, GA(2)LEN and AllerGen). Allergy. 2008;63 Suppl 86:8-160.

3. Fokkens WJ, Lund VJ, Mullol J, Bachert C, Alobid I, Baroody F, et al. European Position Paper on Rhinosinusitis and Nasal Polyps 2012. Rhinol Suppl 2012;23:1-298.

4. Shaaban R, Zureik M, Soussan D, Neukirch C, Heinrich J, Sunyer J, et al. Rhinitis and onset of asthma: a longitudinal population-based study. Lancet. 2008;372(9643):1049-57.

5. Meltzer EO, Blaiss MS, Naclerio RM, Stoloff SW, Derebery MJ, Nelson HS, et al. Burden of allergic rhinitis: allergies in America, Latin America, and AsiaPacific adult surveys. Allergy Asthma Proc. 2012;33 Suppl 1:S113-41.

6. Schwindt CD, Settipane R. Allergic rhinitis (AR) is now estimated to affect some 1.4 billion people globally and continues to be on the rise. Editorial. Am J Rhinol Allergy. 2012;26 Suppl $1: S 1$.

7. Canonica GW, Bousquet J, Mullol J, Scadding GK, Virchow JC. A survey of the burden of allergic rhinitis in Europe. Allergy. 2007;62 Suppl 5:17-25.
8. Nathan RA. The burden of allergic rhinitis. Allergy Asthma Proc. 2007;28:3-9.

9. Meltzer EO, Nathan R, Derebery J, Stang PE, Campbell UB, Yeh WS, et al. Sleep, quality of life, and productivity impact of nasal symptoms in the United States: findings from the Burden of Rhinitis in America survey. Allergy Asthma Proc. 2009;30:24454.

10. Walker S, Khan-Wasti S, Fletcher M, Cullinan P, Harris J, Sheikh A. Seasonal allergic rhinitis is associated with a detrimental effect on examination performance in United Kingdom teenagers: case-control study. J Allergy Clin Immunol. 2007;120:381-7.

11. Lamb CE, Ratner PH, Johnson CE, Ambegaonkar AJ, Joshi AV, Day D, et al. Economic impact of workplace productivity losses due to allergic rhinitis compared with select medical conditions in the United States from an employer perspective. Curr Med Res Opin. 2006;22(6):1203-10.

12.• Maspero J, Lee BW, Katelaris CH, Potter PC, Cingi C, Lopatin A, et al. Quality of life and control of allergic rhinitis in patients from regions beyond western Europe and the United States. Clin Exp Allergy. 2012;42(12):1684-96.

A review of different HRQoL outcomes assessed in allergic rhinitis patients beyond western Europe and North America.

13. Baiardini I, Bousquet PJ, Brzoza Z, Canonica GW, Compalati E, Fiocchi A, et al. Recommendations for assessing patient-reported outcomes and health-related quality of life in clinical trials on allergy: a GA(2)LEN taskforce position paper. Allergy. 2010;65(3):290-5. 
14. Braido F, Bousquet PJ, Brzoza Z, Canonica GW, Compalati E, Fiocchi A, et al. Specific recommendations for PROs and HRQoL assessment in allergic rhinitis and/or asthma: a GA(2)LEN taskforce position paper. Allergy. 2010;65(8):959-68.

GA2LEN recommendations of relevant patient reported outcomes and HRQoL instruments in allergic rhinitis and/or asthma patients.

15. EMEA(CHMP). Reflection paper on the regulatory guidance for the use of health related quality of life (HRQL) measures in the evaluation of medicinal products. http://www.emea.europa.eu/docs/en_GB/ document_library/Scientific_guideline/2009/09/ WC500003637.pdf

16. World Health Organisation. Constitution of the World Health Organisation. Handbook of basic documents. In:Geneva;1948,3-20.

17. Schipper H, Clinch JJ, Olweny CLM. Quality of life studies: definitions and conceptual issues. In: Spilker B, editor. Quality of Life and Pharmacoeconomics in Clinical Trials. Philadelphia: Lippincott-Raven Publishers; 1996. p. 11-23.

18. van Oene CM, van Reij EJ, Sprangers MA, Fokkens WJ. Quality-assessment of disease-specific quality of life questionnaires for rhinitis and rhinosinusitis: a systematic review. Allergy. 2007;62(12):1359-71.

19. Canonica GW, Baena-Cagnani CE, Bousquet J, Bousquet PJ, Lockey RF, Malling HJ, et al. Recommendations for standardization of clinical trials with Allergen Specific Immunotherapy for respiratory allergy. A statement of a World Allergy Organization (WAO) taskforce. Allergy. 2007;62(3):317-24.

20. Petersen KD, Kronborg C, Gyrd-Hansen D, Dahl R, Larsen JN, Løwenstein H. Quality of life in rhinoconjunctivitis assessed with generic and disease-specific questionnaires. Allergy. 2008;63(3):284-91.

21. Bousquet J, Bullinger $M$, Fayol C, Marquis P, Valentin B, Burtin B. Assessment of quality of life in patients with perennial allergic rhinitis with the French version of the SF-36 Health Status Questionnaire. Allergy Clin Immunol. 1994;94(2 Pt 1):182-8.

22. Rogkakou A, Villa E, Garelli V, Canonica GW. Persistent Allergic Rhinitis and the XPERT Study. World Allergy Organ J. 2011;4(3 Suppl):S32-6.

23. Canonica GW, Bousquet J, Van Hammée G, Bachert C, Durham SR, Klimek L, et al. Levocetirizine improves health-related quality of life and health status in persistent allergic rhinitis. Respir Med.

2006;100(10):1706-15.

24. Ciprandi G, Canonica WG, Grosclaude M, Ostinelli J, Brazzola GG, Bousquet J. Effects of budesonide and fluticasone propionate in a placebo-controlled study on symptoms and quality of life in seasonal allergic rhinitis. Allergy. 2002;57(7):586-91.

25. Passalacqua G, Pasquali M, Ariano R, Lombardi C, Giardini A, Baiardini I, et al. Randomized double- blind controlled study with sublingual carbamylated allergoid immunotherapy in mild rhinitis due to mites. Allergy. 2006;61(7):849-54.

26. Pfaar O, Kleine-Tebbe J, Hörmann K, Klimek L. Allergen-specific immunotherapy: which outcome measures are useful in monitoring clinical trials? Immunol Allergy Clin N Am. 2011;31(2):289-309.

27. Bousquet J, Scheinmann P, Guinnepain MT, PerrinFayolle M, Sauvaget J, Tonnel AB, et al. Sublingualswallow immunotherapy (SLIT) in patients with asthma due to house-dust mites: a double-blind, placebocontrolled study. Allergy. 1999;54(3):249-60.

28. Petersen KD, Kronborg C, Larsen JN, Dahl R, GyrdHansen D. Patient related outcomes in a real life prospective follow up study: Allergen immunotherapy increase quality of life and reduce sick days. World Allergy Organ J. 2013;6:15.

29. Majani G, Baiardini I, Giardini A, Senna GE, Minale $\mathrm{P}, \mathrm{D}^{\prime}$ Ulisse $\mathrm{S}$, et al. Health-related quality of life assessment in young adults with seasonal allergic rhinitis. Allergy. 2001;56(4):313-7.

30. de Loos DA D, Segboer CL, Gevorgyan A, Fokkens WJ. Disease-specific quality-of-life questionnaires in rhinitis and rhinosinusitis: review and evaluation. Curr Allergy Asthma Rep. 2013;13(2):162-70.

31. Ozdoganoglu T, Songu M, Inancli HM. Quality of life in allergic rhinitis. Ther Adv Respir Dis. 2012;6(1):25-39.

32. Juniper EF, Guyatt GH. Development and testing of a new measure of health status for clinical trials in rhinoconjunctivitis. Clin Exp Allergy. 1991;21(1):77-83.

33. Juniper EF, Guyatt H, Dolovich J. Assessment of quality of life in adolescents with allergic rhinoconjunctivitis: development and testing of a questionnaire for clinical trials. J Allergy Clin Immunol. 1994;93:413-23.

34. Juniper EF, Thompson AK, Ferrie PJ, Roberts JN. Validation of the standardized version of the Rhinoconjunctivitis Quality of Life Questionnaire. J Allergy Clin Immunol. 1999;104(2 Pt 1):364-9.

35. Juniper EF, Rohrbaugh T, Meltzer EO. A questionnaire to measure quality of life in adults with nocturnal allergic rhinoconjunctivitis. J Allergy Clin Immunol. 2003;111(3):484-90.

36. Juniper EF, Thompson AK, Ferrie PJ, Roberts JN. Development and validation of the mini Rhinoconjunctivitis Quality of Life Questionnaire. Clin Exp Allergy. 2000;30(1):132-40.

37. Juniper EF, Howland WC, Roberts NB, Thompson AK, King DR. Measuring quality of life in children with rhinoconjunctivitis. J Allergy Clin Immunol. 1998;101(2 Pt 1):163-70.

38. Corrigan CJ, Kettner J, Doemer C, Cromwell O, Cromwell A, Study Group. Efficacy and safety of 
preseasonal-specific immunotherapy with an aluminium-adsorbed six-grass pollen allergoid. Allergy. 2005;60(6):801-7.

39. Frew AJ, Powell RJ, Corrigan CJ, Durham SR, UK Immunotherapy Study Group. Efficacy and safety of specific immunotherapy with SQ allergen extract in treatment-resistant seasonal allergic rhinoconjunctivitis. J Allergy Clin Immunol. 2006;117(2):319-25.

40. Rak S, Yang WH, Pedersen MR, Durham SR. Oncedaily sublingual allergen-specific immunotherapy improves quality of life in patients with grass polleninduced allergic rhinoconjunctivitis: a double-blind, randomised study. Qual Life Res. 2007;16(2):191201.

41. Didier A, Melac M, Montagut A, Lhéritier-Barrand M, Tabar A, Worm M. Agreement of efficacy assessments for five-grass pollen sublingual tablet immunotherapy. Allergy. 2009;64(1):166-71.

42. Durham SR, Yang WH, Pedersen MR, Johansen N, Rak S. Sublingual immunotherapy with once-daily grass allergen tablets: a randomized controlled trial in seasonal allergic rhinoconjunctivitis. J Allergy Clin Immunol. 2006;117(4):802-9.

43. Nelson HS, Nolte H, Creticos P, Maloney J, Wu J, Bernstein DI. Efficacy and safety of timothy grass allergy immunotherapy tablet treatment in North American adults. J Allergy Clin Immunol. 2011;127(1):72-80.

44. Blaiss M, Maloney J, Nolte H, Gawchik S, Yao R, Skoner DP. Efficacy and safety of timothy grass allergy immunotherapy tablets in North American children and adolescents. J Allergy Clin Immunol. 2011;127(1):64-71.

45. Baiardini I, Pasquali M, Giardini A, Specchia C, Passalacqua G, Venturi S, et al. Rhinasthma: a new specific QoL questionnaire for patients with rhinitis and asthma. Allergy. 2003;58(4):289-94.

46. Braido F, Baiardini I, Stagi E, Scichilone N, Rossi O, Lombardi C, et al. RhinAsthma patient perspective: a short daily asthma and rhinitis QoL assessment. Allergy. 2012;67(11):1443-50.

47. Valero A, Alonso J, Antépara I, Baró E, Colás C, del Cuvillo A, et al. Health-related quality of life in allergic rhinitis: comparing the short form ESPRINT-15 and MiniRQLQ questionnaires. Allergy. 2007;62(12):1372-8.

48. Valero A, Izquierdo I, Giralt J, Bartra J, del Cuvillo A, Mullol J. Rupatadine improves nasal symptoms, quality of life (ESPRINT-15) and severity in a subanalysis of a cohort of Spanish allergic rhinitis patients. J Investig Allergol Clin Immunol. 2011;21(3):229-35.

49. Reilly MC, Tanner A, Meltzer EO. Work, classroom and activity impairment instruments: validation studies in allergic rhinitis. Clin Drug Investig. 1996;11:278-88.
50. Segall N, Gawchik S, Georges G, Haeusler JM. Efficacy and safety of levocetirizine in improving symptoms and health-related quality of life in US adults with seasonal allergic rhinitis: a randomized, placebo-controlled study. Ann Allergy Asthma Immunol. 2010;104(3):259-67.

51. Bousquet J, Zuberbier T, Canonica GW, Fokkens WJ, Gopalan G, Shekar T. Randomized controlled trial of desloratadine for persistent allergic rhinitis: correlations between symptom improvement and quality of life. Allergy Asthma Proc. 2013;34(3):274-82.

52. Nathan RA, Dalal A, Stanford R, Meltzer EO, Schatz M, Derebery J, et al. Qualitative development of the Rhinitis Control Assessment Test (RCAT), an instrument for evaluating rhinitis symptom control. Patient Patient Cent Outcome Res. 2010;3:91-9.

53. Schatz M, Meltzer EO, Nathan RA, Derebery J, Mintz M, Stanford R, et al. Psychometric validation of the Rhinitis Control Assessment Test (RCAT): a brief, self administered instrument for evaluating rhinitis symptom control. Ann Allergy Asthma Immunol. 2010;104:118-24.

54. Meltzer EO, Schatz M, Nathan R, Garris C, Stanford $\mathrm{RH}$, Kosinski M. Reliability, validity, and responsiveness of the Rhinitis Control Assessment Test in patients with rhinitis. Allergy Clin Immunol. 2013;131(2):379-86.

55. Schatz M, Zeiger RS, Chen W, Yang SJ, Stanford RH, Garris CP. A comparison of the psychometric properties of the Mini-Rhinitis Quality of Life Questionnaire and the Rhinitis Control Assessment Test. Am J Rhinol Allergy. 2012;26(2):127-33.

56. Demoly P, Jankowski R, Chassany O, Bessah Y, Allaert FA. Validation of a self-questionnaire for assessing the control of allergic rhinitis. Clin Exp Allergy. 2011;41(6):860-8.

57. Nogueira-Silva L, Martins SV, Cruz-Correia R, Azevedo LF, Morais-Almeida M, Bugalho-Almeida A, et al. Control of allergic rhinitis and asthma test-a formal approach to the development of a measuring tool. Respir Res. 2009;10:52.

58. Fonseca JA, Nogueira-Silva L, Morais-Almeida M, Azevedo L, Sa-Sousa A, Branco-Ferreira M, et al. Validation of a questionnaire (CARAT10) to assess rhinitis and asthma in patients with asthma. Allergy. 2010;65(8):1042-8.

59. Fonseca JA, Nogueira-Silva L, Morais-Almeida M, SaSousa A, Azevedo LF, Ferreira J, et al. Control of Allergic Rhinitis and Asthma Test (CARAT) can be used to assess individual patients over time. Clin Transl Allergy. 2012;2(1):16.

60. Demoly P, Calderon MA, Casale T, Scadding G, Annesi-Maesano I, et al. Assessment of disease control in allergic rhinitis. Clin Transl Allergy. 2013;3(1):7. 
61. Franzke N, Schäfer I, Jost K, Blome C, Rustenbach SJ, Reich $\mathrm{K}$, et al. A new instrument for the assessment of patient-defined benefit in the treatment of allergic rhinitis. Allergy. 2011;66(5):665-70.

62. Justicia JL, Cardona V, Guardia P, Ojeda P, Olaguíbel JM, Vega JM, et al. Validation of the first treatmentspecific questionnaire for the assessment of patient satisfaction with allergen-specific immunotherapy in allergic patients: the ESPIA questionnaire. J Allergy Clin Immunol. 2013;131(6):1539-46.

63. Turner RR, Testa MA, Hayes JF, Su M. Validation of the allergic rhinitis treatment satisfaction and preference scale. Allergy Asthma Proc. 2013;34(6):551-7.

64. Farnik M, Pierzchała W. Instrument development and evaluation for patient-related outcomes assessments. Patient Related Outcome Measures. 2012;3:1-7.

65. Bousquet J, Schünemann HJ, Samolinski B, Demoly $\mathrm{P}$, Baena-Cagnani CE, Bachert C, et al. World Health Organization Collaborating Center for Asthma and Rhinitis. Allergic Rhinitis and its Impact on Asthma (ARIA): achievements in 10 years and future needs. J Allergy Clin Immunol. 2012;130(5):1049-62. 